\title{
Spinal Subarachnoid Hemorrhage due to a Thoracic Neurinoma during Anticoagulation Therapy -A Case Report-
}

\author{
Masao Motomochi, Yasumasa MaKita, Sachio NabeShima, \\ Tetsuya ITAGaKI and Taikyoku TEI
}

Department of Neurosurgery, Tenri Hospital, Tenri 632

\begin{abstract}
Summary
A case of spinal subarachnoid hemorrhage due to a thoracic neurinoma during anticoagulation therapy is presented. The underlying pathology, clinical course and pertinent literature are reviewed.
\end{abstract}

Key words: Anticoagulation, spinal subarachnoid hemorrhage, thoracic neurinoma, spinal cord tumor

\section{Introduction}

A subarachnoid hemorrhage due to an intraspinal tumor is a rare occurrence. According to Djindjian et al. ${ }^{5)}$, only 45 such cases have been reported in the literature. Ependymomas of the cauda equina are the tumors most commonly asociated with subarachnoid hemorrhages, but other intraspinal tumors such as neurinomas and neurofibromas have also been associated with such hemorrhages in a few instances. This is a report of spontaneous spinal subarachnoid hematoma from a thoracic neurinoma during anticoagulation therapy which was considered to have induced the bleeding.

\section{Case Report}

This 51-year old semi-retired anesthesiologist with rheumatic heart disease had had a tricuspid annuloplication and a mitral valve replacement in June, 1978. In June 1979, he had a presumed cerebral embolus with left hemiparesis and mental confusion, which lasted for several days. Thereafter, he had been on $2.5 \mathrm{mg}$ to $1.5 \mathrm{mg}$ of warfarin daily per os, with the prothrombin time controlled between 16 and 20 seconds. He stated that he had experienced repeated attacks of right lower thoracic back pain for 2 years prior to this admission.
On the morning of September 19, 1979, when coming back from a walk, he suddenly noticed severe right thoracic pain and numbness in the right leg which soon extended up to the level of the umbilicus. The numbness developed also in the left lower extremity to a lesser extent. In a few hours, he developed urinary retention, abdominal distention and weakness of the bilateral lower extremities. On the following day, he was referred to our service via a nearby hospital.

Upon physical examination at admission, the patient was somewhat cachectic with a body weight of $42 \mathrm{~kg}$, height of $167 \mathrm{~cm}$, and a tendency of moderate kyphosis. There was marked cardiomegaly; cardiac pulse was visible upon the bilateral anterior chest wall and upper abdomen. Pulse rate was 70 per minute and very irregular; respiration was 20 and of the costoabdominal type; and blood pressure was 98/70.

There was a spastic paraparesis more marked on the right side with bilateral Babinski's toe sign. Sensory testing disclosed hypalgesia to $\mathrm{T}-12$ more on the right side, and hypesthesia to $\mathrm{T}-10$ more on the right side. Severe tenderness was noted in the right $\mathrm{T}-10$ paravertebral region. The abdomen was distended due to paralytic ileus and an urethral catheter had been inserted because of urinary retention. Anal sphincter tonus was moderately hypotonic. Positive routine laboratory test values included 
RBC: $2.74 \times 10^{6} / \mathrm{cmm}, \mathrm{Ht}: 27.6 \%, \quad \mathrm{NPN}$ : $32 \mathrm{mg} / \mathrm{dl}$ and prothrombin time: $16.6 \mathrm{sec}$ (control: $10.8 \mathrm{sec}$ ). Chest $\mathrm{X}$-rays showed marked cardiomegaly with pulmonary fibrosis. Electrocardiogram showed atrial fibrillation with arrhythmia perpetua. Urgent lumbar myelography revealed a complete block at $\mathbf{T}-10$, which indicated an intradural mass on the right side displacing the cord (Fig. 1). The CSF looked pinkish and was not removed.

Emergency laminectomies were carried out covering $\mathrm{T}-8$ through $\mathrm{T}-11$. This disclosed a hematoma clot, $3 \times 2 \times 1 \mathrm{~cm}$ in size, under the arachnoid membrane located at levels from $\mathrm{T}-8$ through $\mathrm{T}-10$ on the right side compressing the spinal cord to the opposite side. There was a pea-sized brownish gray mass buried in the hematoma, loosely adherent to the right $\mathrm{T}-10$ nerve root (Fig. 2). Both the hematoma and mass were totally removed. A histological study proved the latter to be a neurinoma with hemosiderin deposits (Fig. 3).

The patient recovered well postoperatively. He became able to urinate and defecate without difficulties in a few days. He started to ambulate without assistance in the following 2 weeks, when neither motor nor sensory impairment was noted. No anticoagulant was given postoperatively for fear of re-bleeding. On October 20 , however, he suddenly fell into a semicoma with respiratory distress and left-sided hemiplegia. A CT scan 2 days later showed a huge infarction in the right frontotemporal region.

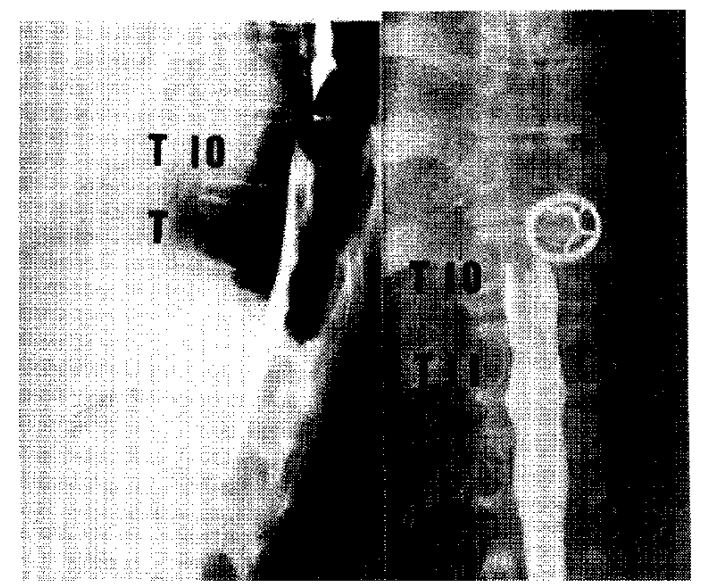

Fig. 1 Ascending myodil myelograms of P-A and lateral views showing a complete block at $\mathbf{T}-10$, suggesting an intradural mass.
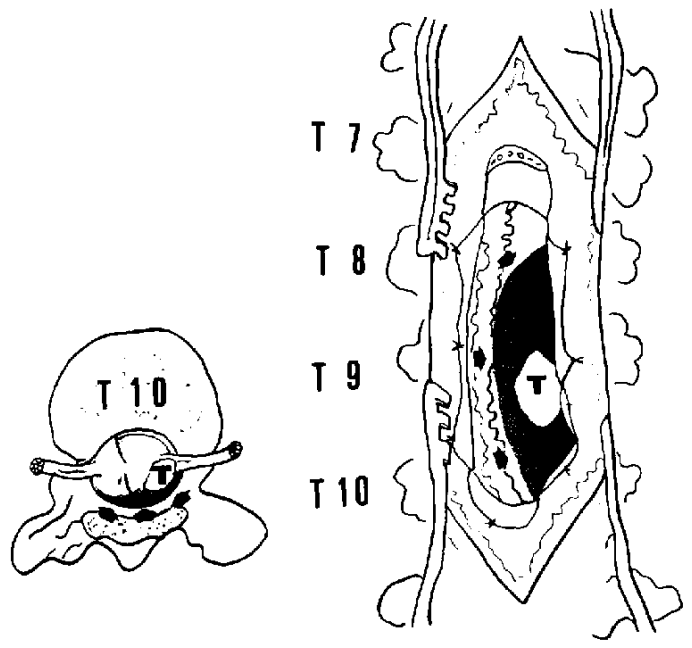

Fig. 2 Drawings showing extension of the subarachnoid blood clot (three arrows) and location of the T-10 thoracic neurinoma on the right side $(T)$.

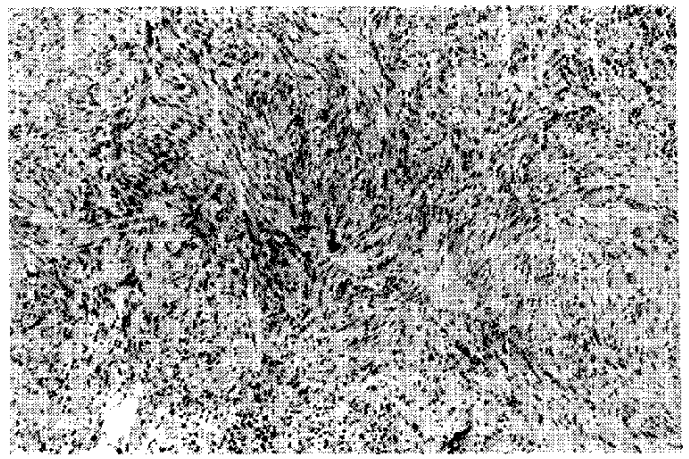

Fig. 3 Photomicrograph of the neurinoma with hemosiderin deposits. H \& E, $\times 120$

He eventually expired on November 9 because of an evident complication of disseminated intravascular coagulation (DIC). No autopsy could be performed. The postoperative complications were presumed to be due to discontinuation of anticoagulation therapy.

\section{Discussion}

Neurological complications of anticoagulation therapy were discussed by Silverstein. ${ }^{19)} \mathrm{He}$ suggested that the typical complications are intracranial subdural hematoma, intraspinal epidural hematoma, and femoral nerve compression due to bleeding into the iliac muscle in the peripheral nerves. In fact, one of the preoperative differential diagnosis in our case 
Table 1 Spinal cord tumors causing subarachnoid hemorrhages

\begin{tabular}{|c|c|c|c|c|c|c|c|c|}
\hline \multirow{2}{*}{ Type of tumor } & \multirow{2}{*}{ Males } & \multirow{2}{*}{ Females } & \multirow{2}{*}{ Total } & \multirow{2}{*}{ Average age } & \multicolumn{4}{|c|}{ Location } \\
\hline & & & & & $\mathrm{C}$ & $\mathbf{T}$ & $\mathrm{T}-\mathrm{L}$ & LS \\
\hline Ependymoma & 14 & 10 & $24(55.8 \%)$ & 24.3 & & 1 & 4 & 19 \\
\hline Neurinoma & 7 & 1 & $8(18.6 \%)$ & 37.5 & 1 & 3 & & 4 \\
\hline Neurofibroma & 3 & 2 & $5(11.6 \%)$ & 42.5 & & & 2 & 3 \\
\hline Hemangioblastoma & 1 & & $1(2.3 \%)$ & 30.0 & & & & 1 \\
\hline Neurospongioma & & 1 & $1 \quad(2.3 \%)$ & 15.0 & & & & 1 \\
\hline $\begin{array}{l}\text { Angioblastic } \\
\text { meningioma }\end{array}$ & 1 & & $1(2.3 \%)$ & 34.0 & & & & 1 \\
\hline $\begin{array}{l}\text { Pilocytic } \\
\text { astrocytoma }\end{array}$ & 1 & 1 & $2 \quad(4.7 \%)$ & 14.8 & 1 & 1 & & \\
\hline $\begin{array}{l}\text { Meningio- } \\
\text { blastoma }\end{array}$ & 1 & & $1(2.3 \%)$ & 8.0 & & & & 1 \\
\hline Total & 28 & 15 & $43(99.9 \%)$ & 28.1 & 2 & 5 & 6 & $\begin{array}{r}29 \\
\| \\
9.8 \%\end{array}$ \\
\hline
\end{tabular}

was an epidral hematoma. The neurinoma was located in the middle of the subarachnoid hematoma clot, which naturally led us to conclude that the bleeding should have been from the tumor. The anticoagulation must have been an inducing factor for the bleeding. According to the available literature including our case, 43 cases of spinal cord tumors have caused spinal subarachnoid hemorrhages ${ }^{1-18)}$ (Table 1). Of these, 24 cases $(55.8 \%)$ were ependymomas, eight neurinomas, four neurofibromas, two pilocytic astrocytomas and one each of hemangioblastoma, neurospongioma, angioblastic meningioma, and meningioblastoma. The ependymomas were all located in the conus medullaris and filum terminale, usually with multiple subarachnoid hemorrhages and attacks of sciatica characteristic of Fincher's syndrome ${ }^{6)}$; the average age was 24.3 years and the male/female ratio $7 / 5$.

The neurinomas causing subarachnoid hemorrhages were located at various levels of the spine with an average age of 37.5 years and a male/female ratio of $7 / 1$; they were much more preponderant in males. Spinal cord tumors causing subarachnoid hemorrhages are frequently associated with papilledema $^{2,6,7,9,11,13)}$ and hydrocephalus, ${ }^{1,2.7 .13)}$ which are attributed to high protein in CSF. Frequently, cerebral four vessel studies seeking cerebral aneurysms precede myelography even in the presence of spinal symptoms only because of subarachnoid hemorrhages. ${ }^{5)}$ Our case was unique with respect to the anticoagulation therapy, which had induced a subarachnoid hemorrhage from the spinal cord tumor, which has so far not been recorded in the literature.

\section{References}

1) Abbott, K. H.: Subarachnoid hemorrhage from an ependymoma arising in the filum terminale. Bull Los Angeles Neurol Soc 4: 127-132, 1939.

2) Arseni, C. A. and Maretsis, M.: Tumors of the lower spinal cord associated with increased intracranial pressure and papilledema. $J$ Neurosurg 27: 105-110, 1967.

3) Bernell, W. R., Kepes, J. J. and Clough, C. A. : Subarachnoid hemorrhage from malignant Schwannoma of cauda equina. Tex Med 69: 101-104, 1973.

4) Bhandari, Y. S.: Subarachnoid hemorrhage due to cerbical cord tumor in a child. $J$ Neurosurg 30: 749-751, 1969.

5) Djindjian, M., Djindjian, R., Houdart, R. and Hurth, M.: Subarachnoid hemorrhage due to intraspinal tumors. Surg Neurol 9: 223-229, 1978.

6) Fincher, E. F.: Spontaneous subarachnoid hemorrhage in intradural tumors of the lumbar sac. $J$ Neurosurg 8: 576-584, 1951.

7) Gibberd, F. B., Ngan, H. and Swann, G. F.: Hydrocephalus, subarachnoid hemorrhage and ependymomas of the cauda equina. Clin Radiol 23: 422-426, 1972.

8) Grollmus, J.: Spinal subarachnoid hemo- 
rrhage with Schwannoma. Acta Neurochirurgica 31: 253-256, 1975.

9) Halpern, L., Feldman, S. and Peyser, E.: Subarachnoid hemorrhage with papilledema due to spinal neurofibroma. Arch Neurol Psychiat 79: 138-141, 1958.

10) Krayenbühl, H.: Spontane spinale Subarachnoidalblutung und akute Rückenmarkskompression bei intraduralem, spinalem Neurinom. Schweiz Med Wochenschr 77: 692-694, 1947.

11) Luxon, L. M. and Harrison, J. G.: Subarachnoid hemorrhage and papilledema due to a cervical neurilemmoma. $J$ Neurosurg 48: 1015-1018, 1978.

12) Mendelsohn, R. A. and Mora, F.: Spontaneous subarachnoid hemorrhage caused by ependymoma of the filum terminale. $J$ Neurosurg 15: 460-463, 1958.

13) Nasser, S. I. and Correll, J. W.: Subarachnoid hemorrhage due to spinal cord tumors. Neurology 18: 87-94, 1968.

14) Nijensohn, D. F., Laventman, J., Miller,
R. H. and Gomex, M. R. : Repeated "occult" spinal subarachnoid hemorrhage and spinal cord ependymoma. Minn Med 57: 697-699, 1974.

15) Payne, N. S., II and McDonald, J. V.: Rupture of spinal cord ependymoma. $J$ Neurosurg 39: 662-665, 1973.

16) Prieto, A. and Cantu, R. C.: Spinal subarachnoid hemorrhage associated with neurofibroma of the cauda equina. $J$ Neurosurg 27: 63-69, 1967.

17) Rice, J. F., Shields, C. B., Morris, C. F. and Neely, B. D.: Spinal subarachnoid hemorrhage during myelography. $J$ Neurosurg 48: 645-648, 1978.

18) Runnels, J. B. and Hanbery, J. W.: Spontaneous subarachnoid hemorrhage associated with spinal cord tumor. I Neurosurg 39: 252-254, 1974.

19) Silverstein, A.: Neurological complications of anticoagulation therapy. Arch Intern Med 139: 217-220, 1979. 